\title{
Ferroelastic crystals as effective acoustooptic materials
}

\author{
Vlokh R. and Martynyuk-Lototska I. \\ Institute of Physical Optics, 23 Dragomanov St., 79005 Lviv, Ukraine; \\ E-mail: vlokh@ifo.lviv.ua
}

Received: 23.03 .2009

\begin{abstract}
In this paper we analyse acoustooptic properties of ferroelastic crystals. It is shown that proper ferroelastics are the most attractive materials for utilisation in acoustooptic devices, due to low velocities of acoustic waves caused by anomalous behaviour of elastic properties in the vicinity of phase transition. A number of new ferroelastic compounds promising for acoustooptic applications are described.
\end{abstract}

Keywords: ferroelastics, acoustooptics.

PACS: 62.65.+k, 62.20.Dc

UDC: 534.4

\section{Introduction}

Parametric crystal optics as a field of physics has been established in 1960-1970 at the interfaces of classical branches already well developed at that time (crystal optics and solid state physics) and a novel one (nonlinear optics). The effects embraced by the parametric optics are in fact nonlinear optical ones, although they take place under the conditions of low-frequency and high-strength external fields and low-intensity optical fields. In spite of the fact that the first parametric optical phenomena (such as piezooptic effect and those discovered by Pockels, Kerr and Faraday) have been known as long ago as 19th century, the scientific branch to which they belong has become mature much later, at the times when strong needs and practical possibilities for controlling laser radiation have appeared.

Almost simultaneously with the intense rise of parametric optics, a wide branch of solid state physics has formed, ferroelectricity and physics of structural phase transitions. A synchronism of appearing of these two branches has not been accidental since just ferroic crystals (ferroelectrics, ferroelastic and ferromagnetics) prove to be the best materials utilised in optoelectronic devices, which are based on the principles of parametric crystal optics. These materials include the crystals which have already become canonical: ferroelectric crystals of lithium niobate, lithium tantalate and KDP used for electrooptic modulation of light, ferromagnetics such as ferrite garnets and orthoferrites used in magnetooptic devices, etc.

Ukr. J. Phys. Opt. 2009, V10, №2 
From this point of view it would be quite logical to assume that ferroelastic materials could be efficiently utilised in acoustooptics. This idea is not novel as it has been developed beginning from the works [1-4]. Actually, the lattice instability in proper ferroelastics with respect to specific acoustic phonons leads to extremely high values of elastic compliances, low values of acoustic wave velocities and, as a result, increasing efficiency of acoustooptic interactions. Let us note that the best acoustooptic material, crystalline paratellurite, also manifests a ferroelastic phase transition, which is practically realised under high hydrostatic pressures [5, 6]. Moreover, this crystal has also a hypothetical ferroelastic phase transition from the prototype cubic phase [7]. The efficiency of acoustooptic interactions is additionally determined by some other parameters, in particular the refractive indices and the photoelastic coefficients. These parameters are also essentially coupled with the ferroic properties of a medium.

Thus, the problem of searching for efficient acoustooptic materials is closely linked with studies of the phase transitions, which are accompanied by deformations of crystalline lattice, softening of acoustic phonons and anomalous behaviour of both the elastic and optical properties. The present report is devoted to comparative analysis of ferroelastic materials, including a number of new compounds that could be successfully employed in acoustooptics.

\section{Criteria for selection of acoustooptic materials}

A principal parameter that defines the acoustooptic efficiency of any material is the acoustoptic figure of merit:

$$
M_{2}=\frac{n^{6} p_{e f}^{2}}{\rho v^{3}}
$$

where $n$ is the refractive index, $p_{\text {ef }}$ the photoelastic coefficient, $\rho$ the density of material and $v$ the acoustic wave velocity. The efficiency of acoustooptic interaction is given by the relation

$$
\eta=I_{d} / I_{0} \propto M_{2} P_{a},
$$

where $I_{0}$ and $I_{d}$ are the intensities of incident and diffracted beams, respectively. It is clearly seen from Eq. (1) that the acoustooptic figure of merit depends mainly on the acoustic wave velocity, which should be as low as possible. Besides, the magnitudes of the effective photoelastic coefficient and the refractive index are also of importance.

Following from the mentioned above, it is reasonable to choose the operating wavelength of optical radiation close to the absorption edge of materials where both the photoelastic coefficients and the refractive indices should be large enough, owing to the dispersion effects. However, the optical absorption also significantly increases under such the conditions. The same contradiction takes place is for the vicinity of proper ferroelastic phase transitions where the acoustic wave velocities decrease notably. Indeed, a decrease in the acoustic wave velocities close to the Curie temperature is usually accompanied by increase in the acoustic attenuation. Moreover, low acoustic velocities impose decreasing 
operation speed of the acoustooptic devices.

The effective photoelastic coefficients are also among the parameters included in Eq. (1). They could be optimised with respect to the acoustic wave polarization so that the resulting magnitude of $p_{e f}$ would be as large as possible for a given material. The attempts of such the approach have been made in the works [8-10]. However, it should be noted that the maximum value of $p_{e f}$ turns out to be related to the polarization of acoustic wave having relatively large velocity which, on the contrary, would lead to decrease in the $M_{2}$ parameter. Furthermore, the acoustooptic interaction for such the wave could in general be not achievable due to absence of conditions for the vector sums.

The density of material also influences the acoustooptic figure of merit. From this viewpoint, packing of heavy chemical elements in the unit cell should be dense enough. On the other hand, there exists another method for increasing acoustooptic figure of merit: in case of some acoustic anisotropy it might be possible to select the slowest acoustic wave for the interaction. Such the approach leads to increase of the $M_{2}$ parameter by an order of magnitude [11]. Hence, searching for principles of selection of the best acoustooptic materials represents rather complicated task, both multi-parametric and ambiguous. Nonetheless, the acoustic wave slowness remains a principal parameter which can greatly increase the efficiency of acoustooptic interactions. The materials where slow ultrasonic waves propagate belong mainly to the ferroelastic family though, of course, they should not be used just under the non-equilibrium conditions of the phase transition.

\section{Comparison of acoustooptic properties of different ferroelastics}

The ferroelastics are crystals that exhibit spontaneous strains of the crystalline lattice appearing at the temperature of structural phase transition and existing in the overall temperature range of ferroelastic phase. This spontaneous strain can be switched by external mechanical stresses. The ferroelastic phase transition is usually driven by the soft acoustic phonon that leads to a drastic lowering of crystal symmetry and a change in its syngony. There are many common features of ferroelastics such as a peculiar domain structure, anomalous behaviours of the elastic stiffnesses and compliances etc., which have been described in many review articles (see, e.g., [12-15]).

In general, ferroelastics represent a wide group of crystalline materials, with the number of representatives not less than that for the groups of ferroelectrics, ferromagnetics, superionic conductors and others. Almost 150 compounds belong to the pure ferroelastics. They are divided into approximately 20 families consisting of crystals with similar structures and isovalent chemical compositions. These families are as follows: langbeinites (the general chemical formula $\mathrm{M}_{2}^{+} \mathrm{M}_{2}^{++}\left(\mathrm{SO}_{4}\right)_{3}$, with $\mathrm{M}_{2}^{+}$and $\mathrm{M}_{2}^{++}$ being respectively univalent and bivalent metal ions [16]), rare-earth molibdates, boracites and tri-hydro-selenites [17], halides with $\beta-\mathrm{K}_{2} \mathrm{SO}_{4}$ structure (or $\mathrm{A}_{2} \mathrm{BX}_{4}$ with 
$\mathrm{X}=$ halogen) [18], cinnabar-type crystals $\left(\mathrm{Hg}_{2} \mathrm{X}_{2}\right.$, with $\mathrm{X}=\mathrm{Br}, \mathrm{Cl}$ or I), palmierites (lead orthophosphates, orthoarsenites and orthovanadates), layered porovskite like crystals $\mathrm{A}_{3} \mathrm{~B}_{2} \mathrm{X}_{9}$ (with $\mathrm{A}$ being alkali metal ion, $\mathrm{B}$ trivalent element and $\mathrm{X}=\mathrm{Cl}, \mathrm{Br}$ or I), fergusonites (for example, $\mathrm{BiVO}_{4}$ and $\mathrm{LaNbO}_{4}$ ), etc.

Many crystals do not have ferroelastic phase transition at the normal conditions, though manifest the ferroelastic transformation under high hydrostatic pressures. For instance, one can refer paratellurite to the latter crystals. Besides, the phase transformation in some crystalline compounds cannot be accessible even under high pressures, though they manifest many properties peculiar for ferroelastics. These are change in the symmetry that needs to assume existence of a prototype phase (e.g., for $\mathrm{BaB}_{2} \mathrm{O}_{4}$ crystals), availability of elastic twins, as well as different symmetries of isostructural crystals with close chemical compositions (e.g., $\mathrm{Hg}_{2} \mathrm{I}_{2}$ does reveals no ferroelastic phase transition, contrary to $\mathrm{Hg}_{2} \mathrm{Br}_{2}$ ). Of course, it would be difficult to analyse exhaustively the acoustooptic parameters of all the ferroelastics, at least because the corresponding literature data are not complete enough. However, one can select the crystals from the families listed above which manifest prominent acoustooptic properties (see Table 1).

For example, the well-known acoustooptic material, tellurium dioxide, exhibits the ferroelastic phase transition from tetragonal to orthorhombic phase under high pressures. This phase transition is accompanied by softening of the acoustic phonon propagated along [110] direction, with the polarization parallel to [1 $\overline{1} 0]$ direction $[5,6]$. Notice that at the normal conditions the maximum acoustooptic figure of merit $\left(1200 \times 10^{-15} \mathrm{~s}^{3} / \mathrm{kg}\right.$ [19]) is achieved right for the case of interaction with the same acoustic wave.

The ferroelastics that represent fergusonite family are $\mathrm{BiVO}_{4}$ crystals. The phase transition in these compounds is driven by softening of the transverse acoustic phonon. Its wave vector lies in (001) plane at the angle of $55^{\circ}$ with respect to [100] direction, whereas its polarization belongs to the same plane. At the $T_{c}$ temperature the velocity of this acoustic phonon acquires a minimum value approximately equal to $300 \mathrm{~m} / \mathrm{s}$, while at the room temperature this velocity increases up to $1800 \mathrm{~m} / \mathrm{s}$. The acoustooptic figure of merit estimated for the interaction with this wave at the room temperature can be as high as $\sim 3400 \times 10^{-15} \mathrm{~s}^{3} / \mathrm{kg}$. It is interesting that even for the much less favourable case of acoustooptic interaction with the longitudinal acoustic wave (the velocity $v_{33}=3990 \mathrm{~m} / \mathrm{s}$ and the propagation direction [001]), the acoustooptic figure of merit for $\mathrm{BiVO}_{4}$ amounts to $415 \times 10^{-15} \mathrm{~s}^{3} / \mathrm{kg}$ [2]. This value is also very high and here high values of the refractive index and the photoelastic coefficient play an important part.

The next compound under our analysis is mercury bromide $\left(\mathrm{Hg}_{2} \mathrm{Br}_{2}\right)$ that belongs to cinnabar-type crystals and possesses the ferroelastic phase transition with the change of point symmetry group $4 / \mathrm{mmm} \mathrm{Fmmm}$. $\mathrm{Hg}_{2} \mathrm{Br}_{2}$ is probably the most efficient acoustooptic material. The acoustooptic interaction with the slowest shear wave propagated in [110] 
Ferroelastic crystals

\begin{tabular}{|c|c|c|c|c|}
\hline 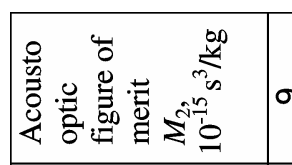 & ه & 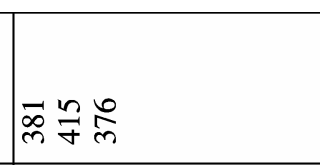 & 过 & 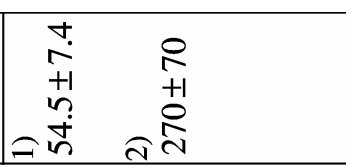 \\
\hline 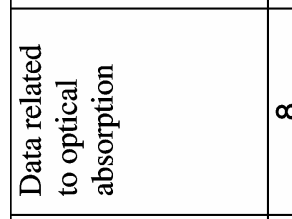 & 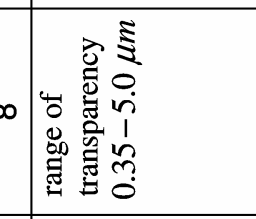 & 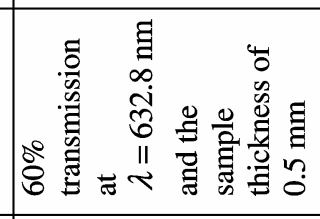 & & 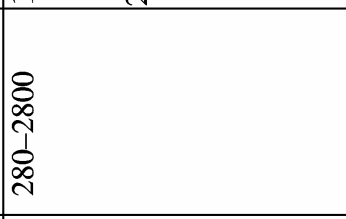 \\
\hline 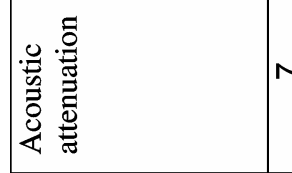 & 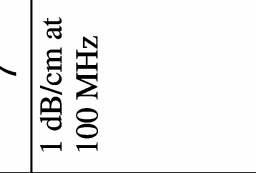 & 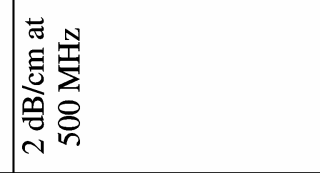 & & \\
\hline 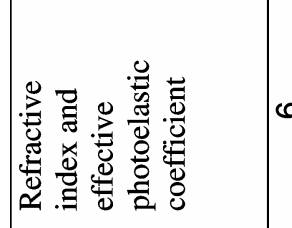 & 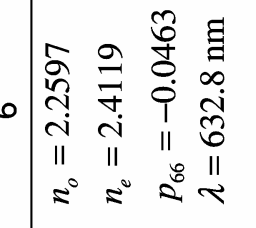 & 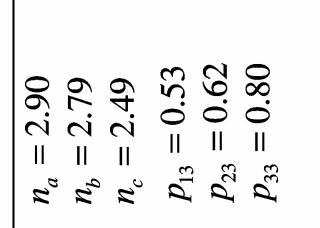 & & 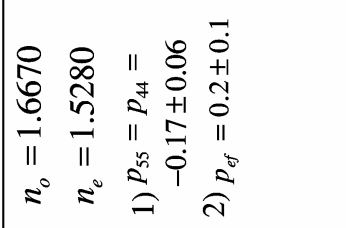 \\
\hline 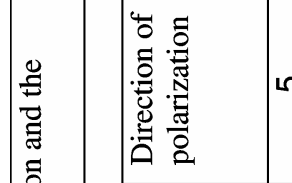 & ○ & 1 & 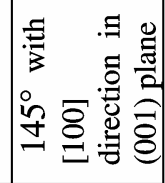 & 步 \\
\hline 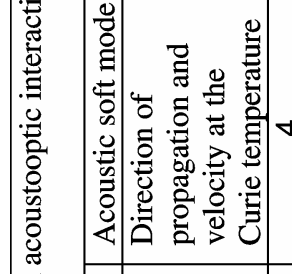 & 次 & 1 & 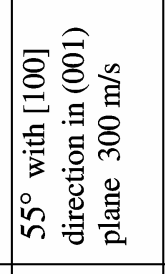 & 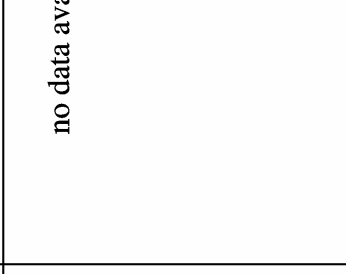 \\
\hline 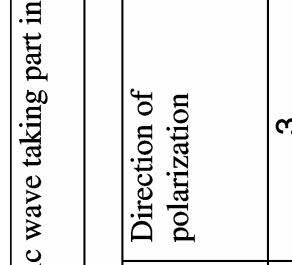 & 恶 & $\overline{\bar{\theta}}$ & 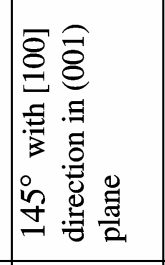 & 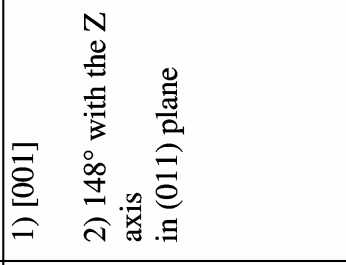 \\
\hline 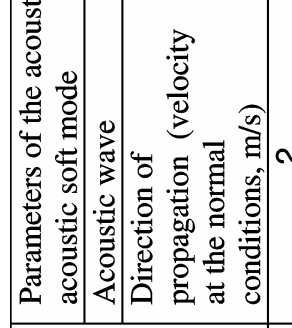 & No & 预高 & 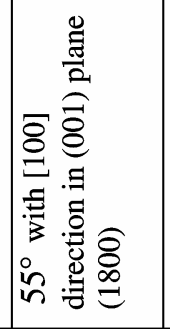 & 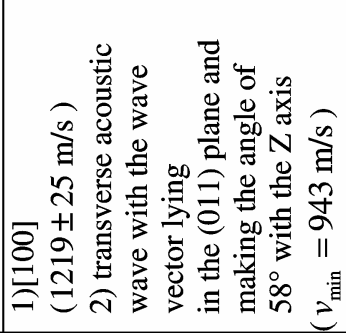 \\
\hline 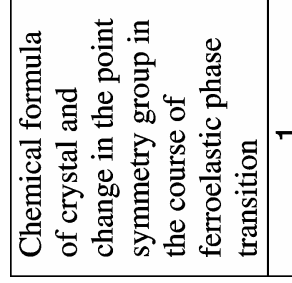 & 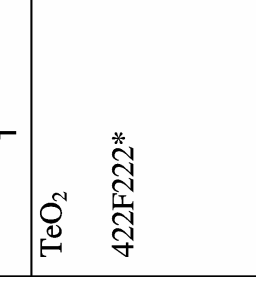 & 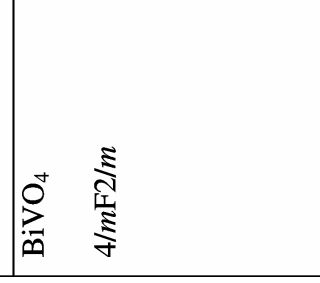 & & 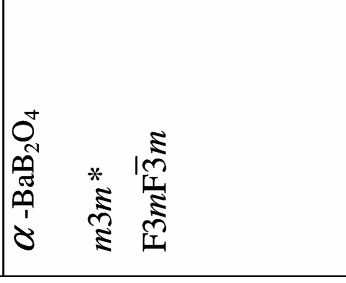 \\
\hline
\end{tabular}

Ukr. J. Phys. Opt. 2009, V10, №2 


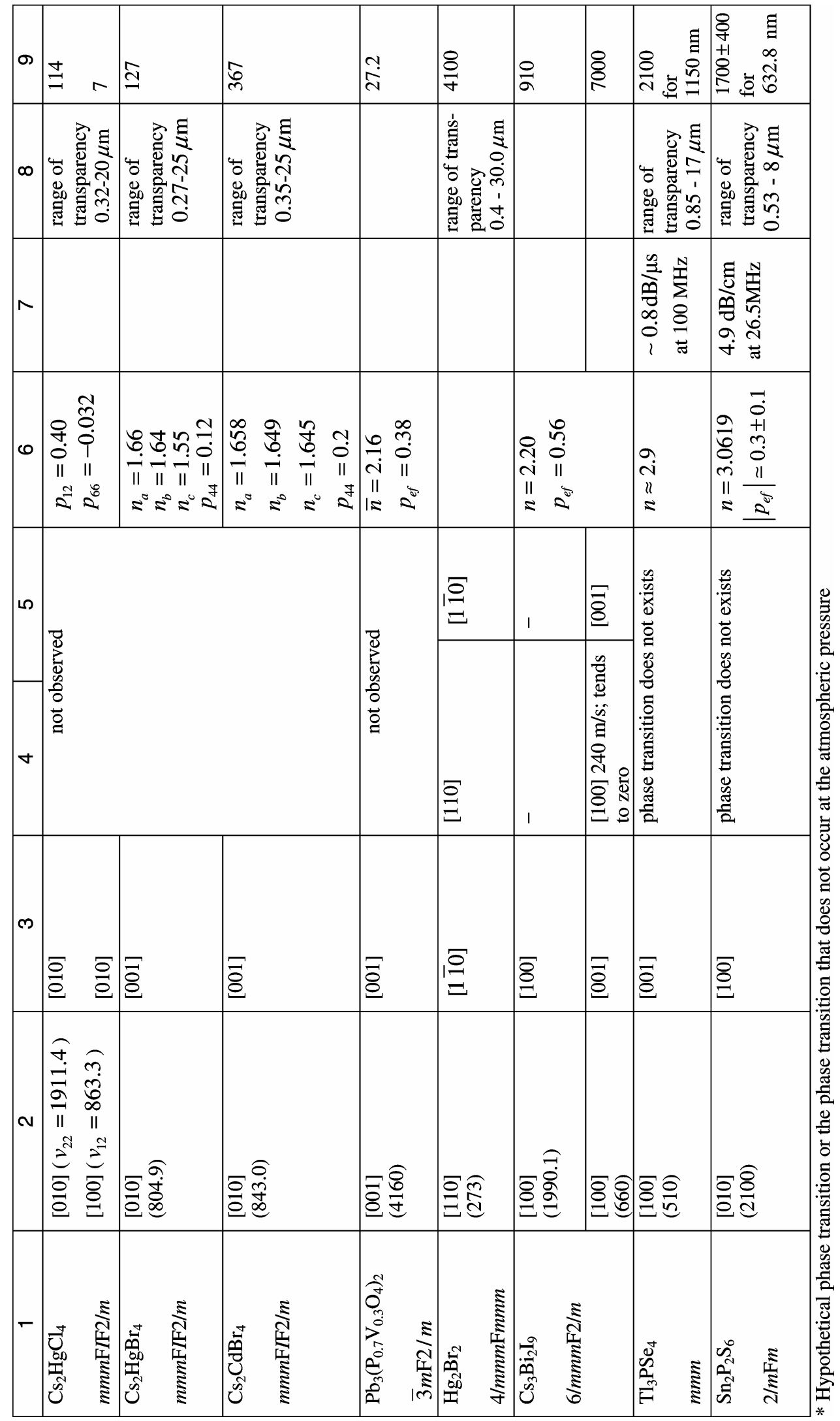

94

Ukr. J. Phys. Opt. 2009, V10, №2 
direction gives rise to the extremely high value of acoustooptic figure of merit, $4100 \times 10^{-15} \mathrm{~s}^{3} / \mathrm{kg}$. The main reason for such a high $M_{2}$ value is that the relevant acoustic wave is very slow (its velocity is equal to $273 \mathrm{~m} / \mathrm{s}[20,21]$ ). Unfortunately, this circumstance also causes low response speed of acoustooptic devices based on $\mathrm{Hg}_{2} \mathrm{Br}_{2}$. This is probably the reason why the $\mathrm{Hg}_{2} \mathrm{Br}_{2}$ crystals have been suggested for utilising in the Bragg cells for a very long-delay signal processing in a compact package, due to extraordinarily low acoustic wave velocity.

The next material we would touch upon is ferroelastic $\mathrm{Cs}_{3} \mathrm{Bi}_{2} \mathrm{I}_{9}$ exhibiting the ferroelastic transformation with the symmetry change $6 / \mathrm{mmmF} / \mathrm{m}$. Regarding the acoustooptic interaction with the longitudinal acoustic wave propagated along [100] direction (the velocity $1990.1 \mathrm{~m} / \mathrm{s}$ ), the acoustooptic figure of merit has been found to be $910 \times 10^{-15} \mathrm{~s}^{3} / \mathrm{kg}$ [22]. This $M_{2}$ coefficient comparable with that for the paratellurite crystals is owing to high values of both the refractive indices and the photoelastic coefficients. Besides, the phase transition in this crystal is probably associated with softening of the acoustic phonon with the wave vector parallel to [100] axis the polarization directed along [001] axis. At least the velocity of the said acoustic wave tends to zero in the vicinity of $T_{c}$, its smallest value observed experimentally being equal to $240 \mathrm{~m} / \mathrm{s}$ [23]. The velocity of this wave at $293 \mathrm{~K}$ increases to $660 \mathrm{~m} / \mathrm{s}$ and the corresponding acoustooptic figure of merit becomes be as high as $\sim 7000 \times 10^{-15} \mathrm{~s}^{3} / \mathrm{kg}$.

The next family of ferroelastic materials, which seems to be reasonable for consideration, is the family of $\mathrm{Cs}_{2} \mathrm{BX}_{4}$ halides with $\beta-\mathrm{K}_{2} \mathrm{SO}_{4}$ structure. These crystals possess ferroelastic phase transformation occurred after passing through intermediate incommensurate phase (this phase is denoted as I in Table 1). The acoustooptic figure of merit can achieve $367 \times 10^{-15} \mathrm{~s}^{3} / \mathrm{kg}$ for $\mathrm{Cs}_{2} \mathrm{CdBr}_{4}[24,25]$ due to rather low velocity $(843 \mathrm{~m} / \mathrm{s})$ of the transverse acoustic wave. Contrary to $\mathrm{Cs}_{2} \mathrm{CdBr}_{4}$ crystals, the interaction with the slowest acoustic wave in iso-structural $\mathrm{Cs}_{2} \mathrm{HgCl}_{4}$ yields in relatively low acoustooptic figure of merit $\left(7 \times 10^{-15} \mathrm{~s}^{3} / \mathrm{kg}\right)$. The highest value for these crystals $\left(M_{2}=114 \times 10^{-15} \mathrm{~s}^{3} / \mathrm{kg}\right)$ may be reached when the optical radiation interacts with the longitudinal acoustic wave propagating along the direction [010] with the velocity $v_{22}=1911.4 \mathrm{~m} / \mathrm{s}$ [26-28]. We have this exceptional result because of the fact that the photoelastic coefficient providing the acoustooptic interaction with the transverse acoustic wave is order of magnitude smaller than the appropriate coefficient referred to the interaction with longitudinal waves. In addition, the refractive indices for all the $\mathrm{Cs}_{2} \mathrm{BX}_{4}$ crystals are not high enough. It is also important that the ferroelastic phase transitions in these crystals are improper.

Another representatives of the improper ferroelastics are lead orthophosphates and orthovanadates. The maximum acoustooptic figure of merit observed for $\mathrm{Pb}_{3}\left(\mathrm{P}_{0.7} \mathrm{~V}_{0.3} \mathrm{O}_{4}\right)_{2}$ crystal is equal to $27.2 \times 10^{-15} \mathrm{~s}^{3} / \mathrm{kg}$ and corresponds to the interaction with the longitudinal wave (the velocity $4160 \mathrm{~m} / \mathrm{s}$ ) [1]. In connection with improper character of 
the phase transitions in lead orthophosphates and orthovanadates, there has been observed no softening of acoustic phonons in the centre of Brillouin zone, the elastic stiffness of these crystals does not approach zero at the Curie temperature and the acoustic wave velocities remain relatively high. This is the reason why the acoustooptic figure of merit for the palmierites is low enough.

Now let us consider the crystals that undergo no ferroelastic phase transitions at the normal conditions (i.e., the transition is hypothetical). $\mathrm{BaB}_{2} \mathrm{O}_{4}$ crystals belong to these materials. $\mathrm{BaB}_{2} \mathrm{O}_{4}$ grows in the two modifications: a non-centrosymmetric lowtemperature (the point symmetry group $3 \mathrm{~m}$ ) and a centrosymmetric high-temperature (the point group $\overline{3} \mathrm{~m}$ ) ones. Usually one needs the non-centrosymmetric modification (a socalled beta-barium borate) for various nonlinear optical applications. If the crystal is grown at high temperatures, the samples obtained are characterised by the group $\overline{3} m$ (an alpha-barium borate). A phase transition between the alpha and beta phases occurs at $\sim 1198 \mathrm{~K}$ under certain conditions [29]. However, this structural phase transition is not completed with decreasing temperature, even down to the room one and so the crystal usually stays in heterophase conditions or remains centrosymmetric, with some nucleus of the acentric phase.

Nonetheless, if the phase transition between the said phases does exist and the symmetries of the phases are not related as group-subgroup, then a prototype phase with some higher symmetry might be chosen, which represents a common parent phase for the both alpha and beta ones. The only higher point symmetry group common for the $\overline{3} m$ and $3 m$ groups is $m 3 m$. Then the phase with the symmetry $\overline{3} m$ is ferroelastic and appears as a result of hypothetical phase transition with the symmetry change $m 3 m \mathrm{~F} \overline{3} m$, while the phase with the symmetry $3 \mathrm{~m}$ is ferroelectric and appear owing to a hypothetical phase transition with the symmetry change $m 3 m \mathrm{~F} 3 m \mathrm{~F} 3 m$. Hence, $\alpha-\mathrm{BaB}_{2} \mathrm{O}_{4}$ crystals may be referred to as ferroelastic materials. Their acoustooptic figure of merit can be as high as $M_{2}=(270 \pm 70) \times 10^{-15} \mathrm{~s}^{3} / \mathrm{kg}$ for the case of acoustooptic interaction with the slowest acoustic wave [11].

$\mathrm{Sn}_{2} \mathrm{P}_{2} \mathrm{~S}_{6}$ crystals have never been considered as ferroelastic and are well-known as proper ferroelectric ones. However, according to the recent data, the twins separated by planar walls appear in the $\mathrm{Sn}_{2} \mathrm{P}_{2} \mathrm{~S}_{6}$ crystals [30]. Rather than for the ferroelectric $180^{\circ}$-domains, these walls are peculiar for the ferroelastic domains that differ by the orientation of principal axes of the spontaneous strain tensor. Following from the orientation of these walls that does not coincide with the principal crystallographic planes (the so called $W^{\prime}$ walls), one can assume that the hypothetical paraelastic phase should have high symmetry $(m 3 m$ or $\overline{4} 3 m)$. Notice that the acoustooptic figure of merit for these crystals has been found to be $(1700 \pm 400) \times 10^{-15} \mathrm{~s}^{3} / \mathrm{kg}$ and the acoustooptic diffraction has been observed for the case of interaction with the transverse acoustic wave (the velocity $2100 \mathrm{~m} / \mathrm{s}$ ) [31]. The high value of acoustooptic figure of merit in the case can be also caused by the 
softening of optical phonon and respective acoustic phonon at ferroelectric phase transition.

The last material we address is $\mathrm{Tl}_{3} \mathrm{PSe}_{4}$ crystal (the point symmetry group $\mathrm{mmm}$ ), with the acoustooptic figure of merit equal to $2100 \times 10^{-15} \mathrm{~s}^{3} / \mathrm{kg}$ [32]. Similarly to the most of cases analysed previously, here the high acoustooptic efficiency is associated with a very slow transverse acoustic wave $(510 \mathrm{~m} / \mathrm{s})$ and a large refractive index. These crystals also manifest no ferroelastic phase transition at the normal conditions. However, the crystalline compounds such as $\mathrm{Tl}_{3} \mathrm{VS}_{4}$ and $\mathrm{Tl}_{3} \mathrm{TaSe}_{4}$, which are iso-structural to $\mathrm{Tl}_{3} \mathrm{PSe}_{4}$, belong to the point group $\overline{4} 3 m$ [19]. Then one can anticipate that a ferroelastic phase transformation with the symmetry change $\overline{4} 3 \mathrm{mFmmm}$ would exist on the concentrationtemperature phase diagram of the corresponding solid solutions, e.g. $\mathrm{Tl}_{3} \mathrm{P}_{\mathrm{x}} \mathrm{Ta}_{1-\mathrm{x}} \mathrm{Se}_{4}$.

\section{Conclusions}

Summing up the results our analysis for the acoustooptic properties of crystals regarded as efficient acoustooptic materials, one can conclude that all of these crystals manifest ferroelastic properties. Owing to low velocities of their acoustic waves caused by elastic instability at the phase transition, softening of the acoustic phonons and anomalous behaviour of the elastic stiffness coefficients, the acoustooptic figure of merit of these crystals can be as high as $10^{-10} \mathrm{~s}^{3} / \mathrm{kg}$ at the phase transition temperature and $10^{-12} \mathrm{~s}^{3} / \mathrm{kg}$ at the normal conditions.

In some cases the photoelastic coefficients could play a crucial part in achieving high acoustooptic figures of merit. This case may be represented by $\mathrm{Cs}_{2} \mathrm{HgCl}_{4}$ crystals. Their photoelastic coefficient concerned with acoustooptic interaction with the slowest acoustic wave is too small. Besides, the anisotropy and high values of photoelastic coefficients should play deciding role for the acoustooptic interactions in case of almost isotropic acoustic wave velocity (for example, for $\mathrm{SrB}_{4} \mathrm{O}_{7}$ and $\mathrm{PbB}_{4} \mathrm{O}_{7}$ crystals [33]). However, this condition usually is not the case for the ferroelastics.

Paratellurite and alpha-barium borate in fact belong to the materials analysed in the present paper and defined as ferroelastics. The semiconductor crystals $\mathrm{Sn}_{2} \mathrm{P}_{2} \mathrm{~S}_{6}$ and $\mathrm{Tl}_{3} \mathrm{PSe}_{4}$ could also be considered as ferroelastic materials due to specific features of their properties. However, the latter fact should be proved experimentally.

\section{References}

1. Dudnik E F and Akimov S V, 1978. Acoustooptical properties of lead orthophosphate single crystals and solid solutions on their basis. Fiz. Tverd. Tela. 20: 2815-2816.

2. Akimov S V, Mnushkina I E and Dudnik E F, 1982. Acoustooptic parameters of the bismuth vanadate. Zh. Tekhn. Fiz. 52: 784-785.

3. Akimov S V, Stolpakova T M, Dudnik E F and Sinyakov E V, 1977. Photoelastic properties of $\mathrm{NaBi}\left(\mathrm{MoO}_{4}\right)_{2}$. Fiz. Tverd. Tela. 19: 1832-1833.

4. Akimov S V, Dudnik E F, Stolpakova T M and Donchenko G V, 1978. Acoustooptic 
features of $\mathrm{LiBi}\left(\mathrm{MoO}_{4}\right)_{2}$. Fiz. Tverd. Tela. 20: 944-945.

5. Peercy P S and Fritz I J, 1974. Pressure-induced phase transition in paratellurite $\left(\mathrm{TeO}_{2}\right)$. Phys. Rev. Lett. 32: 466-469.

6. McWhan D B, Birgeneau R J, Bonner W A, Taub H and Ace J D, 1975. Neutron scattering study at high pressure of the structural phase transition in paratellurite. J. Phys. C: Solid State Phys. 8: L81-L85.

7. Akimov S V, Alkhimov A N, Gorbenko V M, Dudnik E F, Tomchakov A N and Flerova S A, 2007. Twinning in paratellurite crystals. Ferroelectrics. 359: 49-56.

8. Kaidan M V, Tybinka B V, Zadorozhna A V, Andrushchak A S, Schranz W, Sahraoui B and Kityk A V, 2007. The indicative surfaces of the photoelastic effect in $\mathrm{Cs}_{2} \mathrm{HgCl}_{4}$ biaxial crystals. Opt. Mater. 29: 475-480.

9. Kaidan M V, Zadorozhna A V, Andrushchak A S and Kityk A V. 2002. Photoelastic and acoustooptical properties of $\mathrm{Cs}_{2} \mathrm{HgCl}_{4}$ crystals. Appl. Opt. 41: 5341-5345.

10. Pinnow D A, 1970. Guide lines for the selection of acoustooptic materials. IEEE J. Quant. Electr. QE-6: 223-238.

11. Martynyuk-Lototska I, Mys O, Dudok T, Adamiv V, Smirnov Y and Vlokh R, 2008. Acousto-optic interaction in $\alpha-\mathrm{BaB}_{2} \mathrm{O}_{4}$ and $\mathrm{Li}_{2} \mathrm{~B}_{4} \mathrm{O}_{7}$ crystals. Appl. Opt. 47: 3446-3454.

12. Shuvalov L A, 1979. Ferroelastics. Izv. AN SSSR, Ser. Fiz. 43: 1554-1560.

13. Gridnev S A, 2002. Ferroelastic crystals: main properties, influence of defects. Priroda. 6: 22-29.

14. Indenbom V L, 1960. Phase transitions without change of the atom number in the crystal unit cell. Kristallografiya. 5: 115-125.

15. Aizu K, 1969. Possible Species of "Ferroelastic" Crystals and of simultaneously ferroelectric and ferroelastic crystals. J. Phys. Soc. Japan. 27: 387-396.

16. Vlokh R, Vlokh O V, Skab I and Girnyk I, 2002. Optical properties of langbeinites II. Domain structure observation. Ukr. J. Phys. Opt. 3: 215-230.

17. Levanyuk A P and Sannikov D G, 1974. Improper ferroelastics. Usp. Fiz. Nauk. 112: 561-588.

18. Plesko S, Kind $\mathrm{R}$ and Arend $\mathrm{H}$, 1980. New structural phase sequence with incommensurate phases in $\mathrm{A}_{2} \mathrm{BX}_{4}$ halides with $\beta-\mathrm{K}_{2} \mathrm{SO}_{4}$ structure. Phys. Stat. Sol. (a). 61: $87-94$.

19. Shaskolskaya M P, Acoustic crystals. Moscow: Nauka (1982).

20. Singh N B and Duval W M B 1991. Growth kinetics of physical vapour transport processes: Crystal growth of opto-electronic material mercurous chloride. NASA Technical Memorandum. 103788.

21. Singh B, Hopkins R H, Suhre D R, Taylor L H, Rosch W, Gottlieb M, Duval W M B, Glicksman M E and Northrop Grumman, 1999. Physical vapor transport growth of Mercuroushalide crystals for acousto-optic tunable filters. Technical Program. The 128th TMS Annual Meeting \& Exhibition, San Diego, California U.S.A., February 28 - March 4, 36. 
22. Zamkov A V, Zaitsev A I, Parshikov S A and Sysoev A M, 2001. Acoustooptic properties of $\mathrm{Cs}_{3} \mathrm{Bi}_{2} \mathrm{I}_{9}$ crystals. Inorg. Mater. 37: 93-94.

23. Girnyk I, Krupych O, Martunyuk-Lototska I, Motsnyi F and Vlokh R, 2003. Phase Coexistence in $\mathrm{Cs}_{3} \mathrm{Bi}_{2} \mathrm{I}_{9}$ Ferroelastics: Optical, dilatation and ultrasonic velocity s. Ukr. J. Phys. Opt. 4: 165-169.

24. Martynyuk-Lototska I, Dudok T and Vlokh R, 2007. Acoustooptical properties of $\mathrm{A}_{2} \mathrm{BX}_{4}$ crystals $(\mathrm{A}=\mathrm{Cs} ; \mathrm{B}=\mathrm{Hg}, \mathrm{Cd} ; \mathrm{X}=\mathrm{Cl}, \mathrm{Br})$. Ferroelectrics. 351: 105-111.

25. Martunyuk-Lototska I Y, Trach I B, Girnyk I S, Vlokh R O and Vlokh O G, 2006. Thermal expansion and phase transformation observation in $\mathrm{Cs}_{2} \mathrm{BX}_{4}$ crystals. Ferroelectrics. 337: 219-332.

26. Kityk A V, Zadorozhna A V, Shchur Ya I, Martynyuk-Lototska I Yu, Burak Ya and Vlokh O G, 1998. Elastic properties of $\mathrm{Cs}_{2} \mathrm{HgBr}_{4}$ and $\mathrm{Cs}_{2} \mathrm{CdBr}_{4}$ crystals. Aust. J. Phys. 51: 943-957.

27. Kityk A V, Zadorozhna A V, Shchur Ya I, Martynyuk-Lototska I Yu and Vlokh O G, 1998. Lattice instability of $\mathrm{Cs}_{2} \mathrm{HgCl}_{4}$ crystals. I. Elastic properties. Phys. Stat. Sol. (b). 210: 35-45.

28. Kaidan M V, Zadorozhna A V, Andrushchak A S and Kityk A V, 2003. $\mathrm{Cs}_{2} \mathrm{HgCl}_{4}$ crystal as a new material for acoustooptical applications. Opt. Mater. 22: 263-268.

29. Ivleva L I, 1990. Crystal growth at polymorphic transformation in barium metaborate. Kratkie Soobshcheniya po Fizike. 1: 24-26.

30. Grabar A A, 1998. Directional light scattering by domain walls in $\mathrm{Sn}_{2} \mathrm{P}_{2} \mathrm{~S}_{6}$ uniaxial ferroelectrics. J. Phys.: Condens. Matter. 10: 2339-2346.

31. Krupych O, Adamenko D, Mys O, Grabar A and Vlokh R, 2008. Faraday effect in $\mathrm{Sn}_{2} \mathrm{P}_{2} \mathrm{~S}_{6}$ crystals. Appl. Opt. 47: 6040-6045.

32. Gottlieb M, Isaacs T J, Feichtner J D and Roland G W, 1974. Acousto-optic properties of some chalcogenide crystals. J. Appl. Phys. 45: 5145-5151.

33. Martynyuk-Lototska I, Dudok T, Mys O and Vlokh R, 2009. Elastic, piezooptic and acoustooptic properties of $\mathrm{SrB}_{4} \mathrm{O}_{7}$ and $\mathrm{PbB}_{4} \mathrm{O}_{7}$ crystals. Opt. Mater. 31: 660-667.

Анотація. В даній статті представлено аналіз акустооптичних властивостей сегнетоеластичних кристалів. Показано, що власні сегнетоеластики $\epsilon$ найперспективнішими матеріалами для використання в акустооптичних пристроях завдяки низьким швидкостям акустичних хвиль, спричиненим аномальною поведінкою пружних властивостей в околі фазового переходу. В роботі описані нові сегнетоеластичні матеріали, перспективні для акустооптичного використання. 